A N N A L E S

U N IVERSITATIS MARIAE C URIE-SKŁODOW S K

L U B L I N - P O L O N I A

VOL. XXXIX, 2

SECTIO I

2014

\title{
IWONA KRUPECKA
}

\section{Las categorías de sindéresis y prudencia en el pensamiento de Bartolomé de Las Casas}

The Categories of Sindéresis and Prudence into Thinking Bartolomé de Las Casas

\section{RESUMEN}

Bartolomé de Las Casas es uno de los más reconocidos patridiarios de la idea del diálogo intercultural. En esta ponencia intento analizar cómo Las Casas pudo introducir en su pensamiento tanto el nivel de lo universal - y de ese modo hizo posible el mismo diálogo - como el de lo particular en su dimensión del contexto cultural irreductible. Para lograr esta visión compleja del diálogo Las Casas evocó varios conceptos pertenecientes ala tradición escolástica: la sindéresis, ley natural oprudencia, pero redefiniendo el etapa entre el momento del reconocimiento intuitivo de los principios y el del jucio de la conciencia de la manera que deje de constituir una esfera de la ciencia y, por lo tanto, de la dialéctica y verdad. Al contrario, Las Casas lo muestra como un etapa de la prudencia, es decir, de las creencias probables, relativizadas al contexto social y cultural y por eso relacionado con retórica y razones pragmáticas.

Palabras clave: sindéresis, prudencia, interculturalidad, ley natural, razón práctica

Las categorías de sindéresis y prudencia son, en mi opinión, las de mayor importancia en cuanto al cambio que sucedió en el pensamiento de Bartolomé de Las Casas desde la famosa controversia en Valladolid, 1550-1551. A pesar de la evidente continuidad de la actitud de Las Casas - después de su conversión dedicó toda la vida madura a la defensa de los indígenas antes de la injusticia de los europeos ${ }^{1}$ - es la disputa con Sepúlveda, tal vez por la necesidad de formular argumentos convincentes, que dió un nuevo impulso a su pensamiento

1 En contra de Ramón Menéndez Pidal en su famoso libro, El padre Las Casas. Su dobre personalidad, Madrid 1963, casi todos los investigadores subrayan la continuidad de su pensamiento. Véase p.ej. A. Huerga, Vida y obras, en B. de Las Casas, Obras completas, t. 1, Madrid 1998; H. Someda, Apología e historia. Estudios sobrefray Bartolomé de Las Casas, Lima 2005; P.S. Vickery, Bartolomé de Las Casas. Great Prophet of the Americas, New York 2006. 
y lo empujo hasta afirmaciones revolucionarias en su tiempo ${ }^{2}$. En otras palabras, Las Casas sobrepasó una óptica simple y simplificante de la cristianización, es decir, de definir a los indios por una falta - la falta de la fe, enseñanza, cultura etc., lo que encontramos tanto en su Brevíssima relación de la destrucción de las Indias, como en sus antecesores, p.ej. en el Diaro de Colón ${ }^{3}$-, a la de definirlos como propietarios de una cultura, que aunque distinta del modelo europeo, no se transforma en una anticultura, como en caso de los Canibales de Colón, sino simplemente como "otra" cultura. Aquí se nota un paso crucial para el siglo XVI: la afirmación de la existencia de las culturas, en plural, en lugar de percibirla sólo en singular, como un ideal realizado dentro de la Christianitas que servía para distinguir objetivamente al hombre civilizado del bárbaro. En este artículo quiero subrayar el esfuerzo de Las Casas de "matar dos pajaros de un tiro": afirmar la pluralidad y variedad de las culturas y, a la vez, salvar lo universal bajo el nombre de la ley natural. Para lograrlo Las Casas utiliza la categoría tomista de la sindéresis, pero evitando el peligro de objetivizar la ley natural en una serie de derechos particulares conforme al ideal cristiano y demandas de los colonizadores, que de alguna manera pudo ser el caso de Francisco de Vitoria ${ }^{4}$. Finalmente, Las Casas puede vencer a Sepúlveda con sus propias armas: con el concepto de la prudencia del origen aristotélico.

Tomás de Aquino, y éste es el punto de partida de Las Casas, define la sindéresis como un hábito innato (natural) de reconocer los principios del obrar, o sea la ley natural ${ }^{5}$. Este concepto es fundamental en la réplica 11 de Controversia y en cap. 40-46 de Apologética historia sumaria, dedicados a la prudencia. El mismo Las Casas, como escribió en una carta a los dominicos de Guatemala y Chiapas, reconoció su argumantación "a favor" de la idolatría y sacrificios humanos, que según él no caen en contradicción con la ley natural, por su mayor

${ }^{2}$ Véase sobre todo un artículo crucial de V. Abril Castelló, La bipolarización Sepúlveda-Las Casas y sus consecuencias: la revolución de la duodecima réplica, en La ética en la conquista de América. Francisco de Vitoria y la Escuela de Salamanca, Madrid 1984. Cfr. S. Zavala, Aspectos formales de la controversia entre Sepúlveda y Las Casas, en Valladolid, a mediados del siglo XVI, „Cuadernos Americanos” 1977, Vol. CCXII, n 3, s. 138-150; A. Losada, Observaciones dobre 'La Apologia' de fray Bartolomé de Las Casas (respuesta a una consulta), „Cuadernos Americanos” 1977, Vol. CCXII, no 3, p. 153-158.

3 Lo subraya Tvetan Todorov en La conquista de América. El problema del Otro, México 1998, p. 44-45. Cfr. p.ej. A. Milhou, El indio americano y el mito de la religión natural, en La imagen del Indio en la Europa moderna, Sevilla 1990. Cfr. también un libro clásico de E. O’Gorman, La invención de América. El Universalismo de la Cultura de Occidente, México 1958, p. 88-98.

${ }^{4}$ Véase p.ej. V. Abril Castelló, Los derechos de las naciones según Bartolomé de Las Casas y la Escuela de Salamanca, [en:] B. de Las Casas, Obras completas, t. 6: Apologética historia sumaria 1, Madrid 1992, p. 142-143; F. Fernández Buey, La controversia entre Ginés de Sepúlveda y Bartolomé de Las Casas. Una revisión, "Boletín Americanista" 1992-1993, n 42-43, p. 315-318; L. Pereña, La escuela de Salamanca y la duda indiana, en La ética en la conquista de América, op. cit.

5 St. Thomas de Aquino, Questiones disputatae. De veritate, q. 16, art. 1, www.corpusthomisticum.org/qdv15.html. 
mérito $^{6}$. La pregunta que hay que hacer es la siguiente: ¿en qué modo, técnicamente, disponiendo de determinados conceptos filosóficos de su tiempo Las Casas pudo hacer esta revalorización? Y también, ¿hasta qué punto sigue en el relativismo?

En Apologética historia sumaria Las Casas propone una definición siguiente de la sindéresis:

El fin de las virtudes morales es el bien humano, y este bien humano es vivir el hombre según razón cada uno, según el estado que tiene y según lo que pide y requiere aquel estado. El cual fin no lo ponen de nuevo los hombres, sino que el Hacedor de la naturaleza imprimió en nuestra razón práctica ciertos principios naturalmente claros, y notas que nadie puede ignorarlas por la lumbre que tiene cada uno en su ánimo, que es el entendimiento que llaman agente, si totalmente no es ligado en el uso de la razón, como en los niños y bobos y mentecaptos; y estos principios, así natos y claros, son los fines de las morales virtudes, son también los preceptos de la ley natural, contenidos todos en un hábito que llaman los teólogos sindéresis, impreso en nuestra mente, y aquélla es la centella de la lumbre del ya dicho entendimiento agente, como si estuviesen en un vaso de cristal o de vidrio muy transparente ${ }^{7}$.

El ser humano reconoce natural e intuitivamente los principios de obrar que tienen el carácter, como lo subraya Las Casas, más universal. La primera y básica regla de la ley natural según tradición tomista es "proseguir el bien y huir del mal"8, de la cual se derivan otras. Esta regla tiene complemento en una constatación siguiente: las cosas a que tenemos una inclinación natural juzgamos buenas, mientras las que nos dan asco juzgamos malas. Podría parecer que de esta manera se abre el camino recto hacia una forma muy arraigada del etnocentrismo. Es obvio que los europeos connotaban, tanto su asco al sacrificio humano, como su deseo de "cuidar" de la propiedad indígena, como inclinaciones naturales. Mientras tanto Las Casas se oponía precisamente a esta conclusión. Lo hizo aprovechando otros elementos de la filosofía tomista.

Primero, distinguió tres inclinaciones básicas, que vinculadas con la ley natural, delimitan los actos humanos: 1. a "la conservación de su ser según la naturaleza de cada una [cosa]"; 2. a "la conservación de la especie de cada uno" (y estas inclinaciónes son propias del ser humano y de otras creaturas vivas), 3. al conocimiento de la verdad y entre otras de la verdad sobre Dios; está es la inclinación especificamente humana, que se une con la 4. al vivir en comunidad, de la manera que ambas producen un interés especial por las cosas humanas, p.ej. por las reglas de conviven-

${ }^{6}$ Véase R. Hernández Martin, Personalidad teológico-jurídica de Bartolomé de Las Casas, "Ciencia Tomista" 2007, t. 134, no 432, p. 81-82.

7 B. de Las Casas, Apologética historia sumaria, lib. III, cap. 40, Fundación el Libro Total, p. 550-551, www.ellibrototal.com/ltotal/?t=1\&d=4072_4167_1_1_4072.

${ }^{8}$ St. Thomas de Aquino, De veritate, q. 16, art. 2; B. de Las Casas, Apologética ..., lib. III, cap. 40, op. cit., p. 552.

${ }^{9}$ B. de Las Casas, Apologética..., lib. III, cap. 40, op. cit., p. 553. 
$\mathrm{cia}^{10}$. Hay que tomar en cuenta que Las Casas, siguiendo a Tomás de Aquino, trata de garantizar a las leyes naturales el carácter más universal, al contrario de Vitoria, que derivaba de la ley natural las leyes particulares, como el derecho de comercio, o la mezclaba con la ley divina, como en el derecho de cristianización ${ }^{11}$.

Segundo, también conforme a la tradición tomista, Las Casas asemeja la decisión moral al razonamiento silogístico, en el cual en función de la premisa mayor se encuentra el principio universal de la ley natural, y en premisa menor, los elementos del conocimiento moral. De esta manera el juicio de la conciencia o el jucio del libre albedrío sobre un acto concreto son conclusiones del razonamiento basado tanto en reconocimiento de la regla universal (la sindéresis) como en el conocimiento moral del sujeto y su orientación en circunstancias particulares del obrar, p.ej. en sus afectos. Es claro, que este modo de conceptualizar la acción humana es posible únicamente dentro de la perspectiva intelectualista: si la razón es el poder que presenta a la voluntad el objeto del deseo, los errores en acto se derivan de los errores en conocimiento, asi que potencialmente se les puede eliminar a través de la discusión, negociaciones etc., que hace posible una cristianización pacífica por enseñanza o predicación. En este momento el acto de recibir la fe está privado de un muy significante factor en el pensamiento erasmiano, que para Las Casas pudo ser uno de los puntos de referencia más importantes, es decir, el factor de la gracia de Dios, que todavia era necesaria, pero marginalizada (así como un poco después lo mostró la discusión entre los erasmistas y protestantes frente a los jesuitas, sobre todo en personas de Báñez, Molina o Suárez). Los infieles dejan de ser, por algún motivo -sea por la voluntad de Dios, sea su propio defecto- condenados al estado de inferioridad insuperable por falta cometida, pues, siendo animales racionales, pueden ahora ser instruidos. Además, esto significa que todas las diferencias entre los europeos y los indios no conciernen al nivel voluntario, así que no se puede concebir a los indios como malos por su naturaleza, sino se les reduce a las diferencias entre distintos sistemas del conocimiento moral. Por lo tanto, una de las cuestiones fundamentales en torno a la conquista de América será el tema de la racionalidad del indio. Incluso para Vitoria, que se distanciaba de las formas crueles de la colonización de América, la falta o debilidad de la razón entre los indios fue una premisa hipotética a favor de la soberanía española en el Nuevo Mundo ${ }^{12}$. En este punto Las Casas introducirá un cambio esencial al esquema tomista.

${ }_{10}$ Ibidem, p. 553-555.

${ }^{11}$ Según Vidal Abril Castelló (Los derechos de las naciones..., op. cit., p. 163) en el pensamiento de Las Casas también encontramos esta mezcla de la ley divina y natural; el investigador supone que la única ley absoluta es para Las Casas el derecho de evangelización. Pero a lo largo de este artículo espero demostrar una interpretación contraria: que la ley natural para Las Casas se delimita a unas cuantas reglas formales del pensar y obrar y no contiene directamente el derecho de predicar el Evangelio.

${ }^{12}$ Cfr. Vidal Abril Castelló, Los derechos de las naciones..., op. cit., p. 143-151; S. Zavala, Servidumbre natural y libertad cristiana según los tratadistas españoles de los siglos XVI y XVII, México 1975, p. 80-86; R. Hernández, Francisco de Vitoria y Bartolomé de Las Casas, [en:] Las Casas entre dos mundos, Lima 1993, p. 47-74. 
Entre la sindéresis infalible y la decisión moral aparece el terreno propio de la prudencia:

Y porque como está dicho, en nuestra razón práctica se contienen ciertas conclusiones que son los medios necesarios o las razones de ellos para alcanzar el fin por quien los hombres se mueven a obrar, y para que estos medios se proporcionen a los fines, y cuando y como se deban tomar y usar rectamente de ellos, se requiere alguna virtud en el hombre; aquesta es la prudencia que suele aplicar los principios universales, que son los dichos fines, a las particulares conclusiones operables o que se han de obrar, y disponer convenientemente los medios para alcanzar aquello que se pretende por fin ${ }^{13}$.

Todavía siguiendo a Tomás de Aquino, Las Casas distingue tres actos fundamentales de la prudencia: 1. El consejo (como buscar las resoluciones posibles), 2. El juzgar (como elección de los medios apropiados), 3. El mandar (como aplicación en obrar de lo que antes fue reconocido justo) ${ }^{14}$. Distingue también tres formas básicas de la prudencia: 1. El regir de si mismo (prudencia monástica), 2. El regir de la familia (p. económica), 3. El regir de la ciudad o del reino (p. política $)^{15}$. Hasta aquí podemos encontrarnos más con una presentación de la doctrina tomista que con un pensamiento propio de Las Casas. Sin embargo, para captar la novedad de la actitud de Las Casas, es necesario preguntarnos por las reglas que vienen a dar contenido particular a las leyes naturales, es decir, ¿por qué escogemos este fin concreto y no el otro? En la filosofía de Tomás de Aquino la virtud regulativa para la prudencia es sabiduría, es decir, el hábito de la razón teorética. Sirviéndose de los principios tanto prácticos como teoréticos, la sabiduría logra descubrir las causas últimas del mundo y de la existencia humana, y de esta manera, puede encontrar los fines últimos, por fundamento de la razón práctica. Así pues, entre la sindéresis y el juicio concreto aparecerían los juicios sapienciales como unas determinaciones ciertas del fin justo, concretizadas después por la prudencia depende de las circunstancias individuales del obrar y del conocimiento moral del sujeto. Las decisiones y actos erróneos vienen de la conciencia errónea que, según Tomás de Aquino, está ligada con la conciencia de lo recto, porque el sujeto no puede reconocer su error si no dispone de la verdadera sabiduría (reservada, hay que mencionarlo, para los cristianos que conocen las verdades reveladas) $)^{16}$.

En el pensamiento de Las Casas el elemento de la sabiduría esta extremadamente marginalizado, de manera que a primer plano pasa la diferencia entre la universalidad de la ley natural y la particularidad de cada acción humana. Las Casas se situa en el terreno de la razón práctica, eliminando el juicio sapiencial de la elaboración del juicio moral o de libre albedrío, así que el vinculo entre el conocimiento moral y la sabiduría está cortado. En otras palabras, la premisa menor

${ }_{13}$ B. de Las Casas, Apologética..., lib. III, cap. 40, op. cit., p. 556.

14 Ibídem.

${ }^{15}$ Ibidem, p. 557-558.

${ }^{16}$ Cfr. St. Thomas de Aquino, De veritate, q. 17, art. 4. 
del silogismo no está motivada por los reconocimientos de la razón teorética sino por el jucio probable de la razón práctica relativizada al contexto cultural.

Demostrando que ni la idolatría, ni los sacrificios humanos caen en contradicción con la ley natural, Las Casas argumenta: "porque todos los hombres somos obligados naturalmente a amar y servir a Dios más que a nosotros mismos, y por consiguiente a defender su honra y culto divino hasta la muerte inclusive: pro loco et tempore" "17. En conclusión, Las Casas alega la categoría de la conciencia errónea, la cual dentro de la doctrina tomista obliga tanto como la recta. Pero a consecuencia de la marginalización de la sabiduría, el silogismo (1) "del razonamiento moral", según se lo puede reconstruir de los escritos de Las Casas aparecería así:

1. Cada ser humano debe seguir el bien y evitar el mal. (La ley natural, el hábito de la sindéresis.)

2. El mayor bien es Dios como el fin último. (La virtud de la sabiduría, el conocimiento de las verdades universales derivadas de los principios que refleja una inclinación natural del ser humano.)

C: Cada ser humano debe seguir a Dios como el fin último. (La virtud de la sabiduría.)

Con esta conclusión elaboramos otro silogismo (2):

1. Cada ser humano debe seguir a Dios como el fin último.

2. Dios-x es un dios verdadero. (El concepto concretizado, la razón práctica, la virtud de la prudencia, el juicio probable.)

C: Cada ser humano debe seguir Dios-x. (La virtud de la prudencia).

Por fin, en otro silogismo (3) se puede derivar la conclusión siguiente: "Se debe sacrificiar y", porque "Cada ser humano debe seguir Dios-x" y "A Dios-x le complace el sacrificio de y", en el cual todos los elementos pertenecen a la prudencia. Hay que subrayar, que según Las Casas la premisa segunda del silogismo segundo, siendo concretización del concepto universal y abstracto, no puede ser un juicio sapiencial ni pierde su carácter de juicio probable, ni siquiera si lo confirma la revelación divina. Relacionando lo individual y lo abstracto (por predicar lo abstracto del individuo) en el silogismo moral, a la vez introducimos la probabilidad inevitable relacionada con el orden cultural, es decir, del conocimiento moral como un conocimiento desarollado dentro de una comunidad o de una cultura. El problema consiste pues en que el concepto del dios, asi como el concepto del medio necesario para lograr el fin, es un concepto universal y abstracto, vacío de contenido concreto y sensible, y su función también es formal, porque sirve de principio para relacionar los términos de los jucios prudenciales, p.ej. como en el silogismo (3). (Aquí está la diferencia entre, p. ej. predicar de la nieve que es blanca, como blancura es una generalización/abstracción universal de la experiencia,

17 B. de Las Casas, Controversia entre Las Casas y Sepúlveda, [en:] Obras completas 10: Tratados de 1552, ed. de R. Hernández y L. Galmés, Madrid 1992, p. 176. 
y predicar del Dios-x que es dios, porque en este caso tenemos que ver con el principio formal de obrar que conocemos intuitivamente.)

De esta manera Las Casas vuelve a la frónesis aristotélica en su forma original. Como leemos en la Ética a Nicómaco [1142a]:

Es, pues, la prudencia contraria del hábito que se llama entendimiento, porque el entendimiento considera los principios, para los cuales no hay dar razón, y la prudencia considera las cosas singulares y últimas, las cuales no se comprenden por ciencia, sino por el sentido; no por el particular de cada cosa, sino por tal sentido cual es él con que en las artes matemáticas juzgamos que esta última figura es triángulo ${ }^{18}$.

Refiriéndose a Aristóteles Las Casas de nuevo subraya el elemento de la probabilidad; la prudencia es la virtud principal en cuanto a lo que podría ser distinto de lo que es. Resulta que el conocimiento moral, como una esfera de lo particular e individual, no se caracteriza por ningún tipo de certeza, sino como el terreno de diversas prácticas culturales. Por lo tanto Las Casas se une al giro antidialéctico humanista de la retórica ${ }^{19}$, en lo que podemos encontrar, por una parte, la influencia evidente de Erasmo de Rotterdam y su método de la cristianización pacífica, y por otra, un intento de Las Casas de resolver independientemente de la doctrina erasmista o tomista el problema de la presencia española en América.

Parece que la influencia de Erasmo, a pesar de varios elementos de su doctrina evidentemente presentes en el pensamiento de Las Casas (p.ej. el valor de la vida ejemplar de los misioneros, el postulado de aprovechar las creencias propias de una comunidad en la predicación mostrándolas como analógicas a la religión cristiana, el reconocimiento del acto de recibir la fe como un acto libre de la voluntad etc.), tuvo que estar marginalizada por lo menos durante y después de la disputa en Valladolid sobre todo porque el voluntarismo erasmista hasta algún punto excluía la perspectiva multicultural. Para Erasmo todavía existía la cultura única de la cristianidad aunque el modo de propagarla era retórico por la necesidad de "convertir los corazones" 20 . Al contrario, Las Casas comienza a percibir la cristianización como una conversión en el nivel de la razón práctica: cómo cambiar un juicio probable por otro jucio que parezca más probable que el anterior (como consiste la aceptación del nuevo sistema del conocimiento moral). Desde la perspectiva de los infieles las verdades reveladas del cristianismo no son más que un juicio probable relativizado a la comunidad cristiana. Como Las Casas escribió en la réplica 11 de la Controversia:

18 La Ética de Aristóteles, lib. VI, cáp. 8, trad. del griego y analizada por P.S. Abril, www.cervantesvirtual.com/servlet/SirveObras/12482398660132622976846/index.htm.

19 Cfr. S. Swieżawski, Między średniowieczem a czasami nowymi, Warszawa 2002, p. 15-24.

20 Cfr. J.C.M. de la Hoz, Bartolomé de Las Casas y la "captatio benevolentiae», "Ciencia tomista" 2007, t. 134, nº 433. 
Luego no se dice la opinión probable por respecto de las reglas de la razón simpliciter, sino porque así parece y así lo usan y aprueban los que son estimados por más sabios y más prudentes en cualquiera nación ${ }^{21}$.

Ahora bien, toda la esfera de la acción humana resulta relativizada al contexto cultural - de las normas aceptadas por una comunidad - en el marco de la ley natural, es decir, de los principios abstractos y formales para elaborar el juicio moral. Por lo tanto Las Casas no vacila en mezclar la virtud de la sabiduría con la virtud de la prudencia, y eliminar el nivel del conocimiento teorético y de las normas ciertamente justas. En la réplica 10 escribe:

Por esto dice el filósofo, $2 .^{\circ}$ de las Éticas, que el medio de la virtud es aquel que según los sabios determinaren. Y los sabios se entienden no según la razón especulativa, sino la práctica, y por respecto de las cosas agibles ${ }^{22}$.

Aceptando el punto de vista aristotélico y reduciendo la sabiduría a la prudencia, Las Casas pudo elaborar su famoso razonamiento de efecto sobre causa que fue uno de sus instrumentos en la lucha contra el genocidio en América y a favor de la libertad de los indios. Si cada actuación intencional se basa en la prudencia y si la prudencia no tiene la sabiduría como su fundamento, es decir, no recibe sus fines de la razón teorética sino las establece autonómicamente (dentro del contexto cultural), entonces cualquier orden regulativo de la actuación humana, tanto privada como pública, será una manifestación de la racionalidad. Como leemos en la Apologética historia sumaria:

Dondequiera que hubiere buen regimiento de la casa o familia y de la ciudad, los subjectos de ellas, que son los hombres, ternán prudencia y suficiente razón para regirse y ordenarse a sí mismos por naturaleza, porque sin ésta no es posible haber orden ni gobernación económica ni política, ni alcanzarse el fin de ellas, que es el bien y utilidad y perpetuidad de los hombres ${ }^{23}$.

En definitiva, dondequiera encontremos una actuación libre del ser humano, encontrarémos también una prueba de la racionalidad.

Para resumir estas reflexiones valdría la pena preguntar hasta qué punto sigue Las Casas en su relativismo. La opinión de Tvetan Todorov es muy significante, pues este investigador constata que Las Casas iba de un extremo al otro, es decir, a veces asumía que existía solamente una religión verdadera - la cristiana - y en otras que todas las religiones eran igualmente verdaderas, pero a la vez intraducibles, de ahí que cualquier diálogo intercultural resultara imposible ${ }^{24}$. Parece que a la luz del concepto lascasiano de la sindéresis debemos entender su pensamiento

${ }^{21}$ B. de Las Casas, Controversia ..., op. cit., p. 178.

${ }^{22}$ Ibidem, p. 171.

${ }^{23}$ B. de Las Casas, Apologética ..., lib. III, cap. 41, op. cit., p. 575-576.

${ }^{24}$ Véase T. Todorov, ...op. cit., p. 200-202. 
maduro, desde la disputa en Valladolid, como un intento de evitar ambos extremos tanto en teoría, como en práctica. Para él, la religión, además del orden de la gracia divina, pertenece al orden de la razón práctica, lo que abre varias posiblidades nuevas: de comparar los sistemas de creencias religiosas y morales, de probar la probabilidad de los jucios particulares o de convencer/convertir con ayuda del arte de la retórica. Todo eso sería imposible sin la ley natural, pero definida de una manera muy especial. Si Todorov tiene razón subrayando que para Las Casas la única universalidad posible es la de la idea de lo divino, como tal, al mismo tiempo no toma en cuenta la función de esta idea. Podríamos decir, que en cualquier sistema de creencias la idea de lo divino, así como la idea del medio necesario etc., funciona como un principio o categoría a priori de elaborar el jucio y ordenar la experiencia. Como un principio puramente formal, esta idea puede ser a la vez universal - y por eso hacer posible el diálogo intercultural - y limitativa en cuanto a cada demanda de universalizar la religión o la moralidad de una comunidad, e imponerla a los otros presentándola como si fuera la única religión o moralidad racional, humana, o verdadera. En este momento la diferencia entre la conciencia errónea y la conciencia recta (casi) desvanece, porque entran en la misma diálectica de "lo mismo" y "lo otro", de "lo propio" y "lo ajeno" que la noción del "bárbaro", en la famosa relativización lascasiana de este concepto. Pero por otra parte se abre a la posibilidad de la comunicación intercultural, porque disponemos de un denominador común de distintas prácticas religiosas.

Este rasgo del pensamiento lascasiano se hace más notable al compararlo con dos maestros del siglo XVI: Vitoria y Montaigne, el primero trabajando todavía dentro del esquema tomista y el segundo rechazando completamente la ley natural. En el discurso De Indis Vitoria deriva los derechos de gentes directamente de la ley natural que no es otra cosa que la ley divina reconocida por un ser humano gracias a la luz natural de la razón. Entre otros, de esta manera deriva p.ej. el derecho de la comunicación, del comercio o de gozar del bien común. Pero el derecho privilegiado por Vitoria es el de la cristianización, y aqui encontramos una paradoja, porque a pesar de todo esfuerzo de Vitoria de liberarse de las determinaciones religiosas y culturales, es decir, de la ley positiva divina y humana de las comunidades europeas, para obtener el punto de vista universal del todo genero humano ${ }^{25}$, cuando argumenta por el derecho de la cristianización, las principales razones vienen de la Escritura Sagrada. Incluso más, pues Vitoria admite la posibilidad de la guerra preventiva para garantizar el éxito de la obra cristianizadora. Aunque en el mismo discurso encontramos unas ideas del origen tomista muy similares a las de Las Casas, como la tesis de conciencia errónea, o que el método de predicar la fe tiene que ir a elaborar el jucio probable para los indios, Vitoria se detiene ante la idea revolucionaria de delimitar el derecho de los cristianos de

${ }^{25}$ Véase p. ej. el analisis excelente de P.V.D. Carro, La teología y los teólogos-juristas españoles ante la conquista de América, Salamanca 1951, p. 315-321, 626-639. 
predicar su verdad a los páganos. Podríamos reconstruir su argumentación así: Como nosotros, gracias a la revelación y la sabiduría, sabemos la verdad y el bien mayor, y aquellos, los páganos o bárbaros, no lo saben, hay que tratarlos como a los niños, que muy a menudo no quieren o no pueden reconocer lo más útil para ellos mismos, pero pueden contar con sus padres que les ayuden. Por eso Vitoria escribe sobre la obligación a la correción fraternal como inscrita en la ley natural - aunque es obvio que la deriva de la Biblia - y efectivamente (aunque indirectamente) sobrepone el derecho de la cristianización sobre los demás derechos de gentes, en el modo que conocemos tanto de los escritos de San Agustín, como de las constataciones de Sepúlveda. En el De Indis leemos:

Si los indios, ya sea los príncipes, ya sea el pueblo, impidieran a los cristianos anunciar libremente el Evangelio, los españoles, dando primero razón de ello para evitar el escándalo, pueden predicarles contra su voluntad y trabajar en la conversión de la gente. Incluso, si es necesario para esto, les es lícito aceptar la guerra o inferirla hasta que se les dé oportunidad de predicar libremente el Evangelio de Cristo $^{26}$.

Por lo tanto, según Vidal Abril Castelló, en el caso de Vitoria podemos hablar sobre "la tentación del poder" porque él "se quedó a medio camino, asignando a los naturales del Nuevo Mundo un status de minoría de edad"27. Como tales, quieran o no quieran merecen conocer y aceptar la verdad europea.

En Montaigne, al contrario, parece que no encontramos ninguna forma de la universalidad, aunque muy a menudo se trata de seguir las "contradicciones" de su pensamiento en busca de lo universal. De esta manera, varios investigadores, p.ej. Todorov, ven en sus conceptos de la razón o naturaleza unos "términos absolutos" con los cuales Montaigne introducía a su relativismo un factor estabilizante y hasta se contraponía a si mismo ${ }^{28}$. Pero al leer atentamente su ensayo De los caníbales podemos constatar que tenemos que ver más con un intento del desmantelamiento del modelo cultural europeo desde dentro, y de desbalatar los conceptos fundamentales en ella, como precisamente los de la razón o naturaleza. Cuando Montaigne escribe en De los caníbales, que "[...] cada cual llama barbarie a lo que es ajeno a sus costumbres. Como no tenemos otro punto de mira para distinguir la verdad y la razón que el ejemplo e idea de las opiniones y usos de país en que vivimos" ${ }^{29}$, relativiza todas las reglas del conocer y obrar al contexto

${ }^{26}$ F. de Vitoria, Doctrina sobre los indios, ed. de R. Hernández, Salamanca 2009, p. 109.

27 V. Abril Castelló, Los derechos de las naciones..., op. cit., p. 142.

${ }^{28}$ Véase R. Handler, Of Cannibals and Custom: Montaigne's Cultural Relativism, "Anthropology Today" 1986, Vol. 2, n 5 , p. 12-14.

${ }_{29}$ M. de Montaigne, De los caníbales, en: idem, Ensayos, ed. digital: http://bib.cervantesvirtual.com/servlet/SirveObras/01372719700248615644802/p0000002.htm\#I_36_. La interpretación relativista del pensamiento de Montaigne encontramos p.ej. en un artículo excelente de R. Celestin, Montaigne and the Cannibals. Toward a Redefinition of Exoticism, "Cultural Anthropology" 1990, Vol. $5, n^{\circ} 3$. En el cual el investigador subraya la falta del universal punto de referencia y escribe: 
cultural, poniendo en juego también estas que para él mismo eran fundamentales en sus actos de autodefinirse como un hombre pleno: reflexivo, pero a la vez "de carne y hueso", para usar las palabras de Unamuno. Incluso más, porque debemos considerar el mismo método ensayista de Montaigne como el método que excluye culaquier cierre del pensamiento, cualquier conclusión cierta, es decir, cualquier sístema filosófico ${ }^{30}$. Por lo tanto la misma contradicción inscrita en los ensayos de Montaigne - p.ej. Su racionalismo reflexivo que se contrapone a su crítica del conocimiento, tanto racional, como sensible - resulta una forma perfecta del conocimiento y del relativismo maduro. Este relativismo contendría tres tesis básicas: la primera, que "Comunicación con el ser no tenemos ninguna" 31 , pues nuestros conocimientos siempre son conocimientos de un ser corporal y cultural, determinado por estos ambos factores; la segunda, que nunca podemos ponernos afuera ni de nuestro cuerpo, ni de nuestra cultura, de tal manera que no disponemos del punto de vista divino u objetivo; y la tercera, que a pesar de todas nuestras dudas y del todo escepticismo, un ser vivo está obligado a considerar y practicar varias opiniones, sístemas teoréticos, o reglas morales como verdaderas.

Ahora bien, como Montaigne no admite ninguna forma de la ley natural, llega hasta el punto en el cual el diálogo intercultural resulta imposible como una forma del conocimiento de la Otredad. En las lineas finales de su ensayo, Montaigne presenta un diálogo que tuvo con los Tupinambá, con ayuda de un intérprete, donde vemos: "Yo hablé a mi vez largo tiempo con uno de ellos, pero tuve un intérprete tan torpe o inhábil para entenderme, que fue poquísimo el placer que recibí" 32 . Después describe las relaciones de poder en la sociedad indígena y cierra el texto con las palabras siguientes: "Todo lo dicho en nada se asemeja a la insensatez ni a la barbarie. Lo que hay aquí, es que estas gentes no gastan calzones ni coletos"33. Hay que preguntar ¿qué conocimiento logró obtener Montaigne a través de ese diálogo? Pues si, pero no sobre el Otro, sino sobre las categorías interpretativas de los europeos, que se hicieron visibles sólo al reflejarse en un espejo de la Otredad ${ }^{34}$. El diálogo consistiría pues más en un movimiento de acercarse a nuestros límites interpretativos, tocarlos, casi tropezar contra nuestras determinaciones culturales,

"The very idea of stable laws contradicts an essential aspect of Montaigne's philosophy [...]" (p. 306).

30 Véase C. Randall, Testimony, Translation, Text. Reading Reliably in Montaigne's "Des cannibales", "Modern Language Studies" 1995, Vol. 25, nº 2, p. 34-44, y también R. Sendyka, Nowoczesny esej. Studium historycznej świadomości gatunku, Kraków 2006, p. 205-246.

${ }_{31}$ M. de Montaigne, Apología de Raimundo Sabunde, ed. digital: http://bib.cervantesvirtual. com/servlet/SirveObras/01372719700248615644802/p0000004.htm\#I_76_.

${ }_{32}$ M. de Montaigne, De los caníbales, op. cit.

33 Ibídem.

${ }^{34}$ Por ejemplo P. Soehlke Heer en el El Nuevo Mundo en la visión de Montaigne o los álbores del anticolonialismo, Caracas 1993, subraya el elemento del reconocimiento de las europeas formas del poder como inválidas o injustas al contrastarlas con estas de los indígenas (p. 151-153). 
para volver a sí mismos llevando consigo una conciencia enriquecedora y hasta purificante de la diversidad y relatividad de las normas. El diálogo - sobre todo porque nuestros intérpretes siempre son "torpes" o intransparentes ${ }^{35}$, es decir no hay ningún nivel universal o común entre los representantes de varias culturas sirve de una experiencia personal de auto-crearse o auto-escribirse pero no de un instrumento de conocer $^{36}$.

El concepto lascasiano de la sindéresis introduce esta universalidad pero como un código más formal del pensar y obrar, como tales. El código que para Las Casas juega un papel fundamental, es hacer posible el diálogo en forma de intercambiar las opiniones sobre diferentes reglas culturales, típicas, inmanentes, de diferentes culturas, de entenderlas y hasta mezclarlas. Richard Rorty escribió en uno de sus ensayos que todas las culturas pertenecen a la misma geometría y no se debe percibirlas como sístemas axiomáticos alternativos sino como diferentes prácticas dentro del mismo esquema. Parece que redefiniendo el concepto tomista de la ley natural Las Casas buscaba esta geometría teniendo en cuenta dos objetivos: Primero, reconocer en la cultura indígena precisamente una cultura, y segundo, mostrarla como comprensible, aunque diferente. Es evidente que lo hizo usando los conceptos que disponía, y en los límites que no pudo sobrepasar. Pero a la vez marcó una tercera ruta entre el universalismo paternalista de Vitoria, y el multiculturalismo cuasi "monadológico" de Montaigne. La señal de camino más importante, fue la palabra "probable".

\section{SUMMARY}

Bartolomé de Las Casas is one of the most important representatives of the idea of intercultural dialogue. In this article I will try to analyse in what way Las Casas could introduce into his doctrine both the universality, which is the condition of possibility for the dialogue, and the irreducible particularity connected with the cultural context. In order to create this complex vision of the dialogue Las Casas used the concepts taken from the scholastic tradition, as sinderesis, natural law or prudence, but the novelty of his thought consists in the redefinition of the intellectual process which succeeds between the moment of the intuitive recognition of the principles and the judgment of conscience so that it is not the stage of the science any more but of the probable and prudent believes and thereby does not constitutes the area of the theoretical but practical reason and rhetoric.

Keywords: sindéresis, prudence, interculturality, natural law, practical reason

${ }^{35}$ Como lo presenta S. Greenblatt, The Go-Between, [en:] Marvelous possessions. The Wonder of the New World, Chicago 1991, p. 146-150.

${ }^{36}$ Cfr. R. Celestin, op. cit., p. 309-310. 